\title{
ANALISIS PENINGKATAN NILAI KUAT GESER TANAH GAMBUT DENGAN BAHAN STABILISASI ABU AMPAS TEBU DAN KAPUR
}

\author{
Berlin Bondan Pratama ${ }^{1}$, Okrobianus Hendri ${ }^{2}$ dan Fatma Sarie ${ }^{3}$ \\ ${ }^{123}$ Program Studi Teknik Sipil, Fakultas Teknik, Universitas Palangka Raya \\ E-mail: berlinb.pratama16@gmail.com¹, okrobianus@gmail.com², \\ fatmasarie@jts.upr.ac.id ${ }^{3}$
}

\begin{abstract}
ABSTRAK
Penelitian ini bertujuan untuk menganalisis sifat fisik tanah gambut pada daerah Jalan Soekarno Palangka Raya sebelum distabilisasi serta menganalisis pengaruh penambahan campuran abu ampas tebu dan kapur terhadap nilai kuat geser tanah gambut. Pemeriksaan sifat fisik tanah meliputi pemeriksaan kadar air, pemeriksaan kadar serat, pemeriksaan berat jenis dan pemeriksaan berat volume. Sedangkan, pemeriksaan sifat mekanik pada tanah asli dan tanah campuran dilakukan dengan uji geser langsung (Direct shear test). Bahan campuran yang digunakan berupa abu ampas tebu dengan variasi 3\%, 6\% dan 12\% ditambah kapur $8 \%$ dari berat sampel dengan pemeraman 3 hari dan 5 hari. Hasil penelitian menunjukkan bahwa tanah gambut di daerah Jalan Soekarno Palangka Raya memiliki nilai kadar air sebesar 262,53\%, kadar serat sebesar 19,05\%, berat jenis sebesar 1,26, dan berat volume sebesar $1,24 \mathrm{~g} / \mathrm{cm}^{3}$. Hasil pengujian geser langsung pada tanah asli didapatkan nilai kohesi (c) sebesar $0,039 \mathrm{~kg} / \mathrm{cm}^{2}$ dan nilai sudut geser dalam $(\phi)$ sebesar $2,06^{\circ}$. Penambahan campuran abu ampas tebu dan kapur pada tanah asli mengakibatkan nilai kohesi dan nilai sudut geser dalam cenderung mengalami peningkatan di setiap penambahan variasi campuran. Peningkatan nilai kohesi (c), sudut geser dalam $(\phi)$ dan kuat geser tanah $(\tau)$ tertinggi terjadi pada penambahan kapur $8 \%+$ abu ampas tebu $12 \%$ pemeraman 5 hari yakni masing-masing sebesar $0,143 \mathrm{~kg} / \mathrm{cm}^{2}$ dan $4,52^{\circ}$, sedangkan untuk nilai kuat geser tanah $(\tau)$ terjadi peningkatan sebesar $153,18 \%$. Hal ini menunjukkan bahwa penambahan campuran abu ampas tebu dan kapur akan memberikan peningkatan terhadap nilai kuat geser tanah, yang mana tanah tersebut menjadi lebih baik dan stabil.
\end{abstract}

Kata Kunci : Tanah gambut, stabilisasi, abu ampas tebu, kapur, kuat geser

\begin{abstract}
This research aims to analyze the physical properties of peat soil in the area of Soekarno Street Palangka Raya before stabilization and to analyze the effect of adding a mixture of bagasse ash and lime to the value of the shear strength of peat soil. Testing the physical properties of the soil includes water content test, fiber content test, specific gravity test and bulk density test. Meanwhile, the testing of the mechanical properties of the original soil and mixed soil is carred out by direct shear test. The mixed material used was bagasse ash with variations 3\%, $6 \%$ and $12 \%$ added lime $8 \%$ of the sample weight with 3 days and 5 days of curing. The result of research showed that the peat soil in the area of Soekarno
\end{abstract}


Street Palangka Raya had a water content value 262,53\%, a fiber content $19,05 \%$, a specific gravity 1,26, and a bulk density $1,24 \mathrm{~g} / \mathrm{cm}^{3}$. The results of direct shear testing on the original soil obtained a cohesion value (c) 0,039 $\mathrm{kg} / \mathrm{cm}^{2}$ and the value of the inner shear angle $(\phi) 2,06^{\circ}$. The addition of a mixture of bagasse ash and lime to the original soil resulted in the cohesion value and internal shear angle value tending to increase with each addition of the mixture variation. The highest increase in cohesion values (c), inner shear angles $(\phi)$ and soil shear strength $(\tau)$ occured with the addition lime $8 \%+12 \%$ bagasse ash curing for 5 days, which were $0,143 \mathrm{~kg} / \mathrm{cm}^{2}$ and 4,52 ${ }^{\circ}$, while for the value of the shear strength of the soil there was an increase 153,18\%. this indicate that the addition of a mixture of bagasse ash and lime will give an increase in the value of the shear strength of the soil, which the soil becomes better than and more stable.

Keywords : Peat soil, stabilization, bagasse ash, lime, shear strength

\section{PENDAHULUAN}

\section{Latar Belakang}

Struktur jalan dan bangunan sering mengalami kerusakan karena kualitas tanah dasar yang kurang kuat untuk mendukung beban diatasnya. Kriteria tanah yang dibutuhkan agar struktur yang dibangun diatas tersebut stabil antara lain daya dukung tanah harus tinggi serta penurunan yang terjadi tidak boleh melebihi penurunan yang diizinkan. Tidak semua jenis tanah memiliki karakteristik yang baik sehingga perlu usaha perbaikan tanah agar pekerjaan konstruksi tetap dapat dilakukan. Salah satu jenis tanah yang kurang baik bagi konstruksi adalah tanah gambut. Tanah gambut merupakan salah satu jenis tanah yang memiliki sifat dan karakteristik yang kurang baik bagi konstruksi. Tanah gambut memiliki sifat fisik tanah yang rendah (angka pori besar, kadar air tinggi, dan berat volume tanah kecil), kuat geser rendah serta kompresibilitasnya sangat besar, sehingga jika menerima beban akan terjadi penurunan yang sangat besar dalam waktu yang relatif pendek. Salah satu usaha untuk memperbaiki sifat tanah dasar adalah stabilisasi tanah. Dalam penelitian ini, stabilisasi tanah yang dilakukan yaitu dengan menambahkan zat aditif abu ampas tebu (Bagasse Ash) dan kapur $(\mathrm{CaO})$. Abu ampas tebu dipilih karena secara fisik memiliki sifat lepas sehingga dapat berfungsi sebagai filler yang bertujuan untuk mengisi pori antar butiran tanah agar lebih stabil (Prasetyo et al., 2018). Abu ampas tebu mengandung unsur $\mathrm{Ca}, \mathrm{Al}$, dan $\mathrm{Mg}$ yang berkontribusi mencegah penyerapan air oleh partikel gambut. Sedangkan, kapur dipilih karena unsur senyawa $\mathrm{SiO}_{2}$ dan $\mathrm{Al}_{2} \mathrm{O}_{3}$ yang terkandung dalam abu ampas tebu bila dikombinasikan dengan kapur akan menyebabkan reaksi pozzolanik di dalam tanah yang distabilisasi (Destamara et al., 2015).

\section{Tujuan Penelitian}

Tujuan yang ingin dicapai dari penelitian ini adalah menganalisis sifat fisik tanah gambut pada daerah Jalan Soekarno Palangka Raya sebelum distabilisasi serta mengetahui pengaruh penambahan campuran abu ampas tebu dan kapur terhadap nilai kuat geser tanah gambut. 


\title{
TINJAUAN PUSTAKA
}

\section{Tanah Gambut}

Tanah gambut (peat soil) secara fisik dikenal sebagai tanah yang mempunyai kandungan bahan organik dan kadar air yang sangat tinggi, angka pori yang besar, dan adanya serat-serat, sedangkan secara teknis yang sangat penting untuk tanah gambut adalah kompresibilitas yang tinggi, terjadinya kompresibilitas primer yang singkat, adanya kompresibilitas akibat creep (kompresibilitas yang terjadi pada tekanan efektif yang konstan), dan kemampuan mendukung beban yang rendah.

Menurut ASTM D-4427 (1992), tanah gambut dapat dibedakan menjadi tiga jenis antara lain sebagai berikut:

1. Fibric yaitu yang mengalami sedikit dekomposisi (gambut mentah) sehingga masih banyak mengandung serabut, kadar serat $>67 \%$.

2. Hemic yaitu mengalami setengah dekomposisi (gambut matang sedang) dan merupakan peralihan dari fibric ke supric. Ciri-cirinya adalah masih mengandung serabut, kadar serat berkisar 33\% - 67\%.

3. Supric yaitu mengalami dekomposisi paling sempurna (gambut mata6ng), kurang mengandung serabut, kadar serat $<33 \%$.

\section{Stabilisasi Tanah}

Stabilisasi tanah adalah usaha untuk meningkatkan kapasitas daya dukung tanah. Apabila tanah terdapat dilapangan bersifat sangat lepas dan sangat mudah tertekan, atau mempunyai indeks konsistensi tidak sesuai, permeabilitas terlalu tinggi, atau sifat lain yang tidak diinginkan sehingga tidak sesuai untuk proyek pembangunan, maka tanah tersebut harus distabilisasikan (Bowles, 1991).

\begin{abstract}
Abu Ampas Tebu
Abu ampas tebu adalah abu yang diperoleh dari ampas tebu yang telah diperas niranya dan telah melalui proses pembakaran. Pembakaran ampas tebu menghasilkan abu ampas tebu yang memiliki kandungan senyawa silika ( $\mathrm{SiO} 2)$. Abu ampas tebu memiliki kandungan $\mathrm{SiO} 2$ yang cukup tinggi, sehingga berpotensi sebagai bahan stabilisasi tanah karena memiliki sifat pozzolan (Mulyati et al., 2012).
\end{abstract}

\section{Kapur}

Kapur adalah kalsium oksida $(\mathrm{CaO})$ yang dibuat dari batuan karbonat yang dipanaskan pada suhu sangat tinggi. Kapur tersebut umumnya berasal dari batu kapur (limestone) atau dolomite. Berdasarkan SNI 03-4147-1996, jenis-jenis kapur dibagi menjadi 4 macam, antara lain:

1. Kapur tipe I yaitu kapur yang mengandung kalsium hidrat tinggi, dengan kadar magnesium oksida $(\mathrm{MgO})$ paling tinggi $4 \%$

2. Kapur tipe II yaitu kapur magnesium atau dolomite yang mengandung magnesium oksida $(\mathrm{MgO})$ lebih dari $4 \%$ dan maksimum $36 \%$ berat

3. Kapur tohor $(\mathrm{CaO})$ yaitu hasil pembakaran batu kapur pada suhu $\pm 90 \square \mathrm{F}$ dengan komposisi sebagian besar kalsium karbonat (CaCO3)

4. Kapur padam, yaitu kapur dari hasil pemadaman kapur tohor dengan air, sehingga terbentuk hidrat $\mathrm{Ca}(\mathrm{OH}) 2$ 


\section{METODE PENELITIAN}

\section{Lokasi Pengambilan Sampel dan Tempat Penelitian}

Lokasi pengambilan sampel tanah gambut yang digunakan terletak di area Jalan Soekarno Kota Palangka Raya. Penelitian dilaksanakan di Laboratorium Mekanika Tanah Fakultas Teknik Universitas Palangka Raya.
Alat Penelitian
Alat-alat yang digunakan dalam penelitian terdiri dari:
1. 1 set alat uji kadar air (ASTM D 2216-71)
2. 1 set alat uji kadar serat (ASTM D 1997-91)
3. 1 set alat uji berat jenis (ASTM D 854-72)
4. 1 set alat uji berat volume (ASTM C 29M-97)
5. 1 set alat uji geser langsung (ASTM D 3080-90)

\section{Bahan Penelitian}

Bahan yang digunakan dalam penelitian ini yaitu sampel tanah gambut, bahan tambah kapur dan abu ampas tebu.

1. Tanah gambut yang digunakan merupakan tanah dalam kondisi tidak terganggu (undisturbed). Sampel tanah tersebut di ambil pada kedalaman $\pm 100 \mathrm{~cm}$ dari permukaan tanah atas dengan menggunakan bor tangan dan tabung penyimpanan sampel.

2. Abu ampas tebu (Bagasse Ash) didapatkan dari hasil pembakaran sisa ampas tebu yang sebelumnya dikumpulkan dari penjual minuman es tebu di sekitar Kota Palangka Raya. Variasi penambahan abu ampas tebu yang ditambahkan adalah 3\%, 6\% dan $12 \%$ dari berat sampel tanah.

3. Kapur yang digunakan dalam penelitian ini adalah jenis kapur tohor $(\mathrm{CaO})$ yang sudah berbentuk bubuk yang bisa didapatkan di toko-toko material. Persentase kapur yang ditambahkan adalah sebesar $8 \%$ dari berat sampel tanah.

\section{Tahap Pengujian Sampel}

Metode yang digunakan dalam penelitian ini adalah metode eksperimen yang direncanakan berdasarkan literatur dari penelitian terdahulu, yaitu tanah gambut dicampur dengan kapur dan abu ampas tebu sebagai bahan tambah dalam stabilisasi tanah gambut dengan persentase penambahan kapur $8 \%$ dan abu ampas tebu sebesar 3\%, 6\%, dan $12 \%$ dari berat tanah.

Variasi campuran bahan uji yang digunakan dalam penelitian ini dapat dilihat pada tabel berikut.

Tabel 1. Variasi Campuran Abu Ampas Tebu dan Kapur pada Tanah Gambut

\begin{tabular}{clc}
\hline No. & \multicolumn{1}{c}{ Variasi } & Keterangan \\
\hline 1 & Tanah Gambut Asli (undisturbed) & $\%$ x Berat Tanah \\
2 & Tanah Gambut + Kapur 8\% + AAT 3\% & $\%$ x Berat Tanah \\
3 & Tanah Gambut + Kapur 8\% + AAT 6\% & $\%$ x Berat Tanah \\
4 & Tanah Gambut + Kapur 8\% + AAT 12\% & $\%$ x Berat Tanah \\
\hline
\end{tabular}

Jumlah sampel untuk masing-masing pengujian disajikan dalam Tabel 2 berikut. 
Tabel 2. Jumlah Sampel pada Tiap Pengujian

\begin{tabular}{llc}
\hline No. & \multicolumn{1}{c}{ Jenis Pengujian } & Jumlah \\
Sampel
\end{tabular}

\section{Pelaksanaan Pengujian Sampel}

Pelaksanaan penelitian yang akan dilalui dalam penelitian ini antara lain:

1. Pekerjaan persiapan

2. Pencampuran bahan uji

3. Pemeraman sampel

4. Pemeriksaan sifat fisik tanah

5. Pemeriksaan sifat mekanik tanah

6. Hasil dan pembahasan.

\section{HASIL \& PEMBAHASAN}

\section{Pemeriksaan Sifat Fisik Tanah Asli}

Hasil pemeriksaan sifat fisik tanah gambut dapat dilihat pada Tabel 3 di bawah ini.

Tabel 3. Hasil Pemeriksaan Sifat Fisik Tanah Asli

\begin{tabular}{clcc}
\hline No. & & Satuan & Hasil \\
\hline 1 & Kadar Air & $\%$ & 262,53 \\
2 & Kadar Serat & $\%$ & 19,05 \\
3 & Berat Jenis & - & 1,26 \\
4 & Berat Volume & $\mathrm{g} / \mathrm{cm}^{3}$ & 1,24 \\
\hline
\end{tabular}

Menurut sistem klasifikasi ASTM D-4427 (1992), tanah gambut yang mempunyai nilai kadar air sebesar 262,53\% termasuk dalam kategori daya serap terhadap air yakni Slightly Absorbent, sedangkan, berdasarkan nilai kadar serat, tanah gambut termasuk ke dalam kategori sapric peat soil (gambut matang) karena memiliki 
nilai kadar serat $<33 \%$. Untuk nilai berat jenis tanah gambut yang didapatkan yakni sebesar 1,26, hal ini sesuai dengan kategori berat jenis tanah gambut, yaitu: 1,25 - 1,80 (Hardiyatmo, 2002).

\section{Pemeriksaan Sifat Mekanik Tanah dengan Uji Geser Langsung}

Pemeriksaan ini dilakukan dengan membandingkan tanah asli dan tanah campuran guna mengetahui pengaruh penambahan campuran terhadap nilai kuat geser tanah gambut.

\section{Uji Geser Langsung Tanah Asli}

Hasil pengujian geser langsung terhadap tanah asli yakni tanah gambut tanpa penambahan bahan campuran disajikan dalam Tabel 4 dan Gambar 1.

Tabel 4. Hasil Uji Geser Langsung Tanah Asli

\begin{tabular}{cccc}
\hline Pengujian & $\begin{array}{c}\text { Kohesi } \\
\left(\mathbf{k g} / \mathbf{c m}^{\mathbf{2}}\right)\end{array}$ & $\begin{array}{c}\text { Sudut Geser Dalam } \\
\left({ }^{\circ}\right)\end{array}$ & $\begin{array}{c}\text { Kuat Geser } \\
\left(\mathbf{k g} / \mathbf{c m}^{\mathbf{2}}\right)\end{array}$ \\
\hline Tanah Asli & 0,039 & 2,06 & 0,173 \\
\hline
\end{tabular}

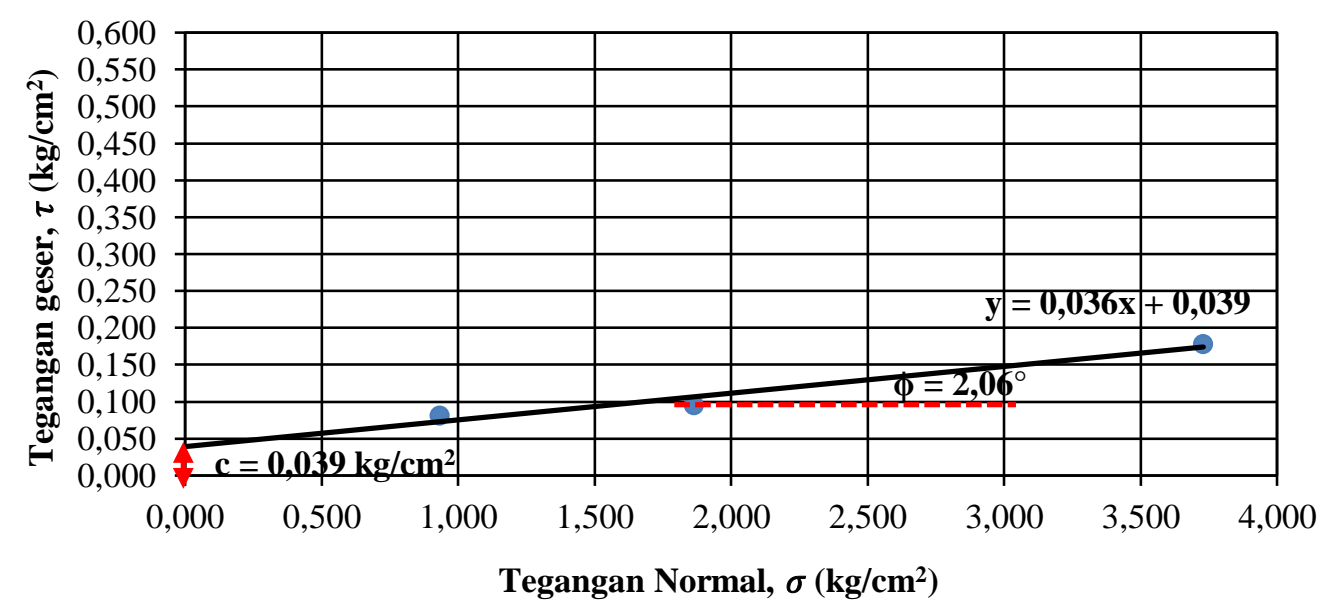

Gambar 1. Grafik Hubungan Tegangan Normal dan Tegangan Geser Tanah Asli

Dari hasil pengujian dan perhitungan uji geser langsung tanah asli yang diperoleh, dapat dilihat bahwa tanah asli yakni tanah gambut di daerah Jalan Soekarno memiliki nilai kohesi, sudut geser dalam dan kuat geser yang rendah, hal ini menunjukkan bahwa daya dukung tanah tersebut rendah, oleh karena itu diperlukan adanya usaha perbaikan tanah asli dengan cara stabilisasi salah satunya dengan stabilisasi secara kimiawi, dalam hal ini digunakan kapur dan abu ampas tebu sebagai bahan campurannya.

\section{Uji Geser Langsung Tanah Campuran}

Hasil pengujian geser langsung terhadap tanah gambut yang telah dicampur dengan bahan stabilitator pada berbagai variasi kadar dan lama pemeramannya dapat dilihat pada Tabel 5 . 
Tabel 5. Hasil Uji Geser Langsung Tanah Campuran

\section{Pemeraman 3 Hari}

\begin{tabular}{lcccccc} 
Pengujian & $\begin{array}{c}\text { Kohesi } \\
\left(\mathrm{kg} / \mathrm{cm}^{2}\right)\end{array}$ & $\begin{array}{c}\text { Sudut } \\
\text { Geser } \\
\text { Dalam } \\
\left({ }^{\circ}\right)\end{array}$ & $\begin{array}{c}\text { Kuat } \\
\text { Geser } \\
\left(\mathrm{kg} / \mathrm{cm}^{2}\right)\end{array}$ & $\begin{array}{c}\text { Kohesi } \\
\left(\mathrm{kg} / \mathrm{cm}^{2}\right)\end{array}$ & $\begin{array}{c}\text { Sudut } \\
\text { Geser } \\
\text { Dalam } \\
\left({ }^{\circ}\right)\end{array}$ & $\begin{array}{c}\text { Kuat } \\
\text { Geser } \\
\left(\mathrm{kg} / \mathrm{cm}^{2}\right)\end{array}$ \\
\hline $\begin{array}{l}\text { Tanah Asli } \\
\text { + Kapur 8\% } \\
\text { + AAT 3\% }\end{array}$ & 0,070 & 3,38 & 0,290 & 0,078 & 4,23 & 0,354 \\
$\begin{array}{l}\text { Tanah Asli } \\
\text { + Kapur 8\% }\end{array}$ & 0,095 & 4,29 & 0,375 & 0,098 & 4,40 & 0,385 \\
+ AAT 6\% & & & & & & \\
$\begin{array}{l}\text { Tanah Asli } \\
\text { + Kapur 8\% }\end{array}$ & 0,119 & 4,46 & 0,410 & 0,143 & 4,52 & 0,438 \\
+ AAT 12\% & & & & & & \\
\hline
\end{tabular}

Pengaruh Bahan Tambah dan Lama Pemeraman terhadap Peningkatan Nilai Kohesi, Sudut Geser Dalam dan Kuat Geser Tanah

Berdasarkan Tabel 5, dibuat grafik perbandingan nilai kohesi (c), sudut geser dalam $(\phi)$ dan kuat geser tanah $(\tau)$ terhadap penambahan abu ampas tebu dan kapur serta lama waktu pemeramannya. Grafik tersebut dapat dilihat pada Gambar 2 sampai dengan Gambar 7.

Pengaruh yang ditimbulkan akibat adanya penambahan abu ampas tebu dan kapur terhadap nilai kohesi (c) dapat dilihat pada Gambar 2 dan Gambar 3 dibawah ini.

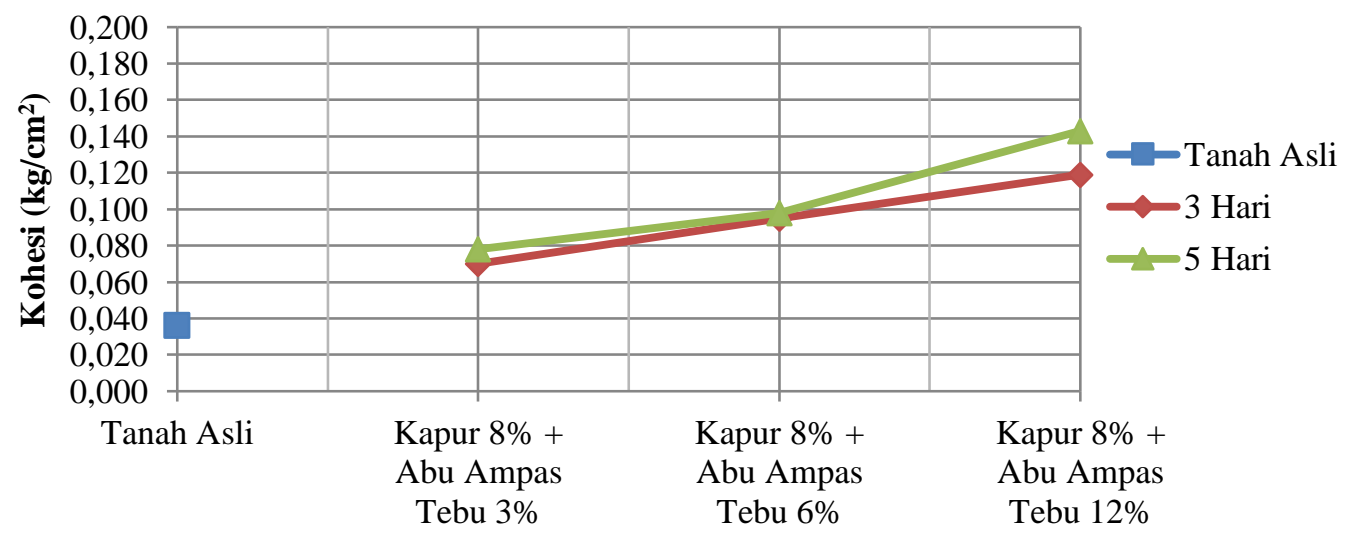

Variasi Campuran

Gambar 2. Grafik Pengaruh Variasi Campuran Kapur dan Abu Ampas Tebu terhadap Nilai Kohesi 
JURNAL KACAPURI

JURNAL KEILMUAN TEKNIK SIPIL

Volume 4 Nomor 2 Edisi Desember 2021

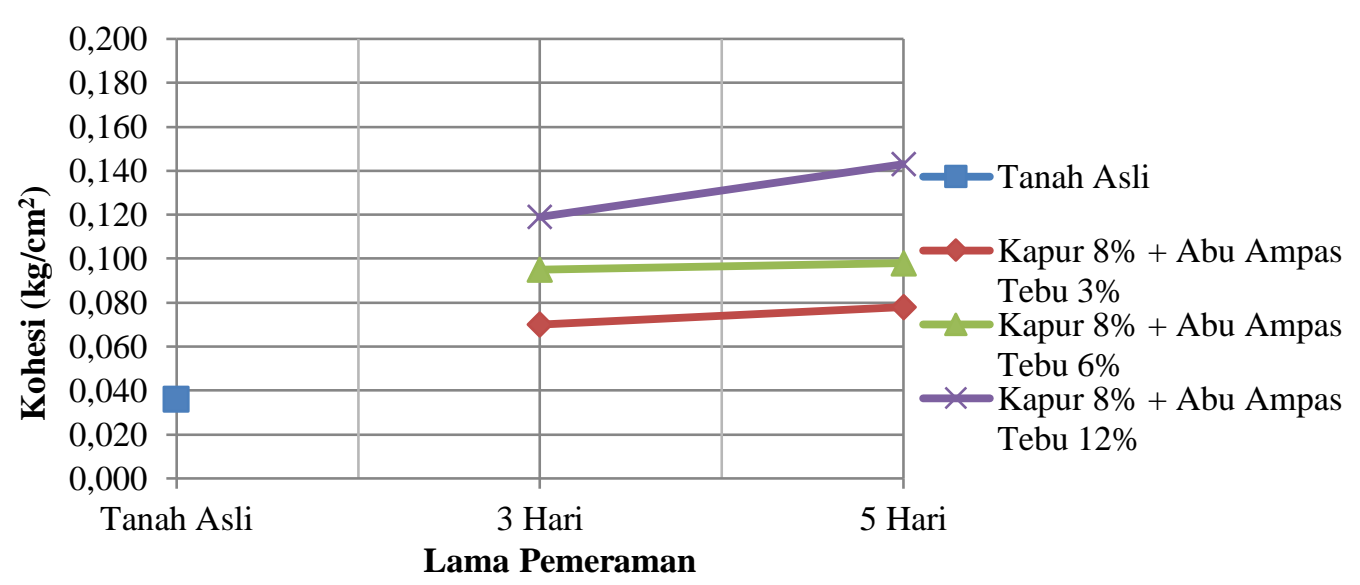

Gambar 3. Grafik Pengaruh Lama Pemeraman terhadap Nilai Kohesi

Berdasarkan beberapa variasi pengujian yang telah dilakukan seperti yang ditampilkan pada Gambar 2 dan Gambar 3 dengan menghubungkan antara variasi campuran abu ampas tebu dan kapur dengan lama waktu pemeramannya, peningkatan nilai kohesi tertinggi terjadi pada penambahan abu ampas tebu $12 \%$ dan kapur $8 \%$ dengan lama waktu pemeraman 5 hari yakni sebesar $0,143 \mathrm{~kg} / \mathrm{cm}^{2}$. Pengaruh yang ditimbulkan akibat adanya penambahan abu ampas tebu dan kapur juga terjadi terhadap nilai sudut geser dalam $(\phi)$ dapat dilihat pada Gambar 4 dan Gambar 5 dibawah ini.

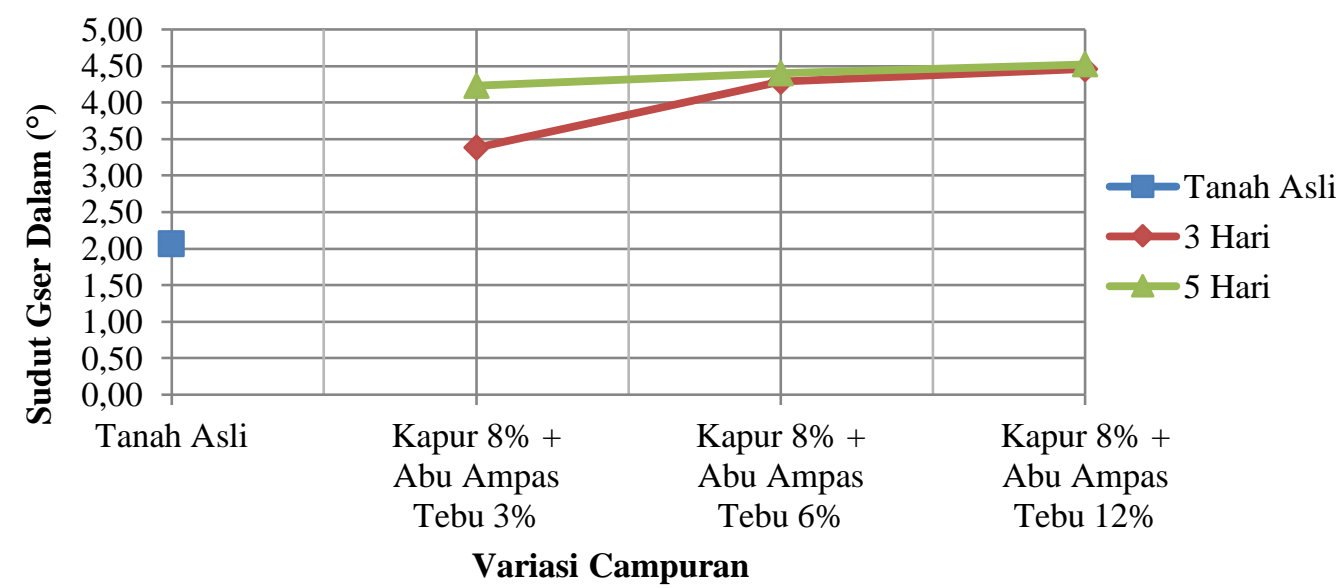

Gambar 4. Grafik Pengaruh Variasi Campuran Kapur dan Abu Ampas Tebu terhadap Nilai Sudut Geser Dalam 
JURNAL KACAPURI

JURNAL KEILMUAN TEKNIK SIPIL

Volume 4 Nomor 2 Edisi Desember 2021

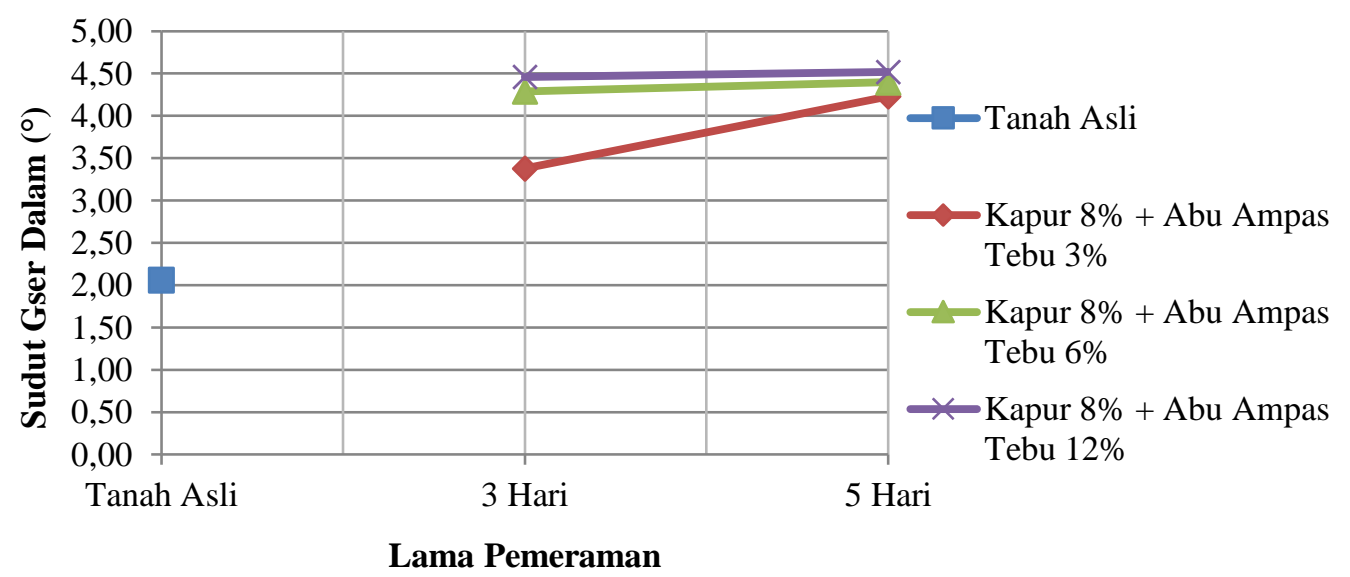

Gambar 5. Grafik Pengaruh Lama Pemeraman terhadap Nilai Sudut Geser Dalam

Berdasarkan Gambar 4 dan Gambar 5, terlihat bahwa penambahan campuran abu ampas tebu dan kapur pada tanah asli juga dapat meningkatkan nilai sudut geser dalam. Peningkatan nilai sudut geser dalam tertinggi terjadi pada penambahan abu ampas tebu $12 \%$ dan kapur $8 \%$ dengan lama waktu pemeraman 5 hari yakni sebesar $4,52^{\circ}$.

Pengaruh yang ditimbulkan akibat adanya penambahan abu ampas tebu dan kapur demikian juga terjadi terhadap nilai kuat geser tanah $(\tau)$ dapat dilihat pada Gambar 6 dan Gambar 7 dibawah ini.

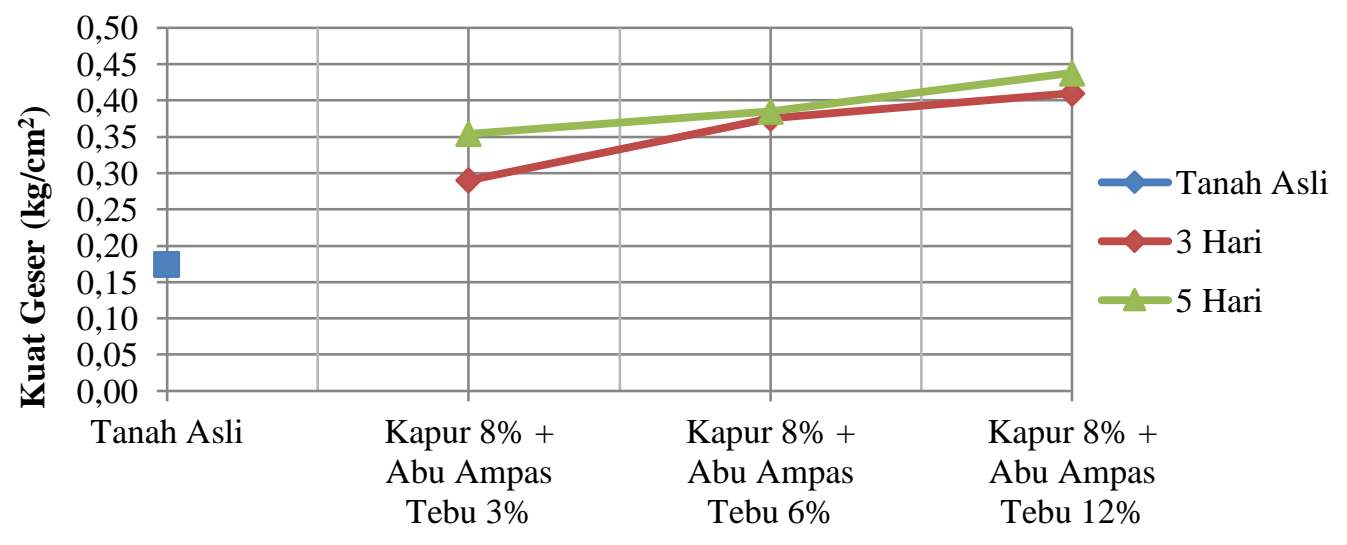

Variasi Campuran

Gambar 6. Grafik Pengaruh Variasi Campuran Kapur dan Abu Ampas Tebu terhadap Nilai Kuat Geser Tanah 
JURNAL KACAPURI

JURNAL KEILMUAN TEKNIK SIPIL

Volume 4 Nomor 2 Edisi Desember 2021

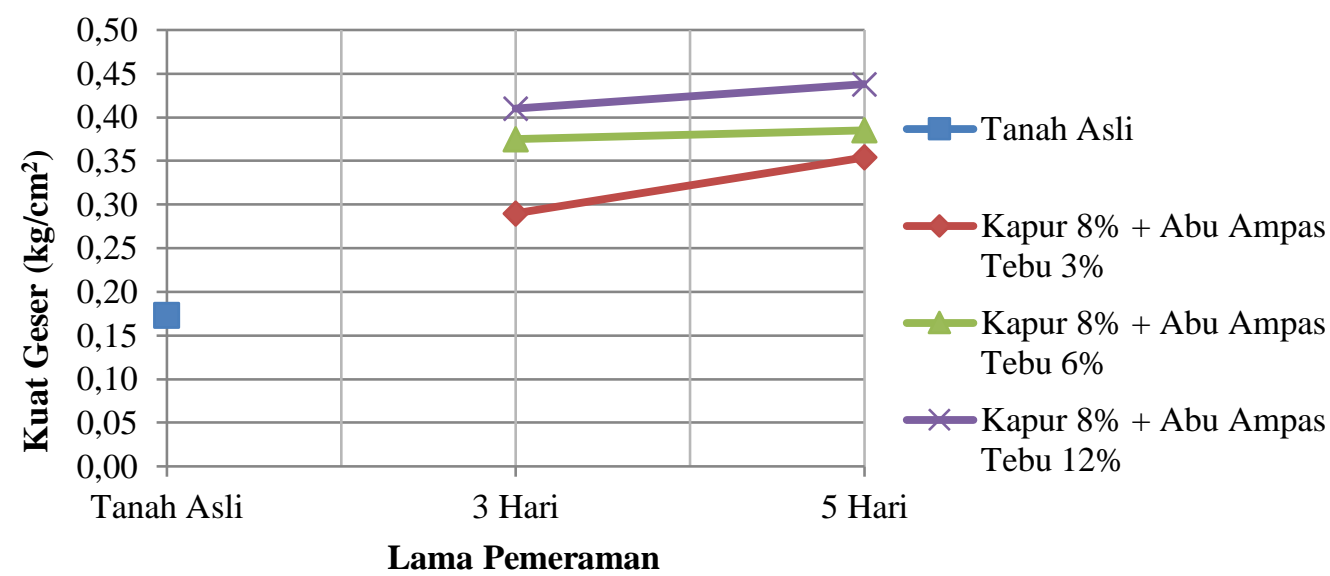

Gambar 7. Grafik Pengaruh Lama Pemeraman terhadap Nilai Kuat Geser Tanah

Berdasarkan Gambar 6 dan Gambar 7 diatas secara keseluruhan, terjadi peningkatan pada setiap penambahan kadar abu ampas tebu beiringan dengan lama waktu pemeraman. Peningkatan nilai kuat geser dalam tertinggi terjadi pada penambahan abu ampas tebu $12 \%$ dan kapur $8 \%$ dengan lama waktu pemeraman 5 hari yakni sebesar $0,438 \mathrm{~kg} / \mathrm{cm}^{2}$.

Peningkatan nilai kohesi, nilai sudut geser dalam dan nilai kuat geser tanah yang terjadi kemungkinan disebabkan oleh campuran dari abu ampas tebu dan kapur, selain itu, dengan bertambahnya lama pemeraman ikatan antar partikel tersebut semakin kuat dan tidak mudah lepas (Panjaitan, 2015). Semakin besar nilai kohesi (c) dan sudut geser dalam $(\phi)$, maka kuat geser tanah $(\tau)$ semakin besar, yang mana tanah tersebut menjadi lebih baik dan stabil sehingga dapat digunakan sebagai tanah dasar suatu bangunan.

\section{PENUTUP}

\section{Kesimpulan}

Berdasarkan hasil penelitian yang telah dilakukan, maka dapat diambil kesimpulan sebagai berikut:

1. Hasil pemeriksaan sifat fisik tanah asli menunjukkan bahwa tanah gambut di daerah Jalan Soekarno Palangka Raya memiliki nilai kadar air sebesar 262,53\%, kadar serat sebesar 19,05\%, berat jenis sebesar 1,26, dan berat volume sebesar 1,24 g/ $\mathrm{cm}^{3}$. Menurut sistem klasifikasi ASTM D-4427 (1992), tanah gambut termasuk ke dalam kategori sapric peat soil (gambut matang) karena memiliki nilai kadar serat $<33 \%$.

2. Hasil pemeriksaan uji geser langsung menunjukkan bahwa penambahan campuran abu ampas tebu dan kapur berpengaruh terhadap nilai kohesi (c) dan nilai sudut geser dalam $(\phi)$ serta nilai kuat geser tanah $(\tau)$. Berdasarkan pengujian geser langsung pada tanah asli didapatkan nilai kohesi (c) sebesar $0,039 \mathrm{~kg} / \mathrm{cm}^{2}$, nilai sudut geser dalam $(\phi)$ sebesar $2,06^{\circ}$ dan $0,438 \mathrm{~kg} / \mathrm{cm}^{2}$ untuk nilai kuat geser tanah $(\tau)$ dimana terjadi peningkatan sebesar $153,18 \%$. Dengan penambahan campuran abu ampas tebu dan kapur pada tanah asli nilai kohesi, nilai sudut geser dalam dan nilai kuat geser tanah cenderung mengalami peningkatan di setiap penambahan persentase abu ampas tebu dan kapur beiringan dengan lamanya waktu pemeraman. Peningkatan tertinggi 
terjadi pada penambahan kapur $8 \%$ + abu ampas tebu $12 \%$ pemeraman 5 hari yakni sebesar $0,143 \mathrm{~kg} . \mathrm{cm}^{2}$ untuk nilai kohesi (c) dan $4,52^{\circ}$, ), serta 0,438 $\mathrm{kg} / \mathrm{cm}^{2}$ untuk nilai kuat geser tanah $(\tau)$ dimana terjadi peningkatan sebesar $153,18 \%$. Hal ini menunjukkan bahwa semakin besar kadar abu ampas tebu yang ditambahkan dan semakin lama waktu pemeraman maka tanah tersebut menjadi lebih baik dan stabil.

\section{Saran}

Berdasarkan penelitian yang telah dilakukan, maka saran yang dapat penulis berikan:

1. Perlu dilakukan penelitian lebih lanjut pemeriksaan sifat fisik pada tanah campuran abu ampas tebu dan kapur.

2. Perlu dilakukan penelitian lebih lanjut mengenai pengaruh bahan tambah campuran abu ampas tebu dan kapur dengan jenis tanah yang sama seperti pengujian CBR, pengujian konsolidasi, dan lain-lain.

3. Penelitian lebih lanjut dengan penambahan variasi persentase abu ampas tebu dan kapur serta penambahan lama waktu pemeraman agar dapat lebih bereaksi.

\section{DAFTAR PUSTAKA}

ASTM (American Society for Testing and Materials) D 2216-71. 1989. Standard Classification of Peat Samples by Laboratory Testing. West Conshochocken. United States.

ASTM (American Society for Testing and Materials) D 4427. 1992. Standard Test Method for Laboratory Determination of Water (Moisture) Content of Soil and Rock By Mass. West Conshochocken. United States.

ASTM (American Society for Testing and Materials) C29/C29M-97. 1997. Standard Test Method for Bulk Density (Unit Weight) and Voids in Aggregate. West Conshochocken. United States.

ASTM (American Society for Testing and Materials) D 3080-90. 1998. Standard Test Method for Direct Shear Test of Soil Under Consolidated Drained Conditions. West Conshochocken. United States.

ASTM (American Society for Testing and Materials) D 854-72. 2002. Standard Test Method for Specific Gravity of Soil Solids by Water Pycnometer. West Conshochocken. United States.

Bowles, J.E. 1991. Sifat-Sifat Fisis dan Geoteknis Tanah (Mekanika Tanah). Edisi Kedua, Penerbit Erlangga. Jakarta.

Destamara, Angger A., Zaika, Yulvi., dan Munawir, A. 2015. Pengaruh Penambahan Abu Ampas Tebu terhadap Karakteristik Tanah Lempung Ekspansif di Bojonegoro. Jurnal Mahasiswa Jurusan Teknik Sipil Universitas Brawijaya. Vol 1 (1) 1-9.

Haras, Melisa., E. Turangan A., dan Legrans, Roski R.I. 2017. Pengaruh Penambahan Kapur terhadap Kuat Geser Tanah Lempung. Jurnal Tekno Jurusan Teknik Sipil Universitas Sam Ratulangi. Vol 15 (67) 77-86. ISSN : 0215-9617. 
Hardiyatmo, H. C. 2002. Mekanika Tanah I. Edisi Ketiga, Gadjah Mada University Press, Yogyakarta.

Mulyati, S., Dahlan, D., dan Adril, E. 2012. Pengaruh Persen Massa Hasil Pembakaran Serbuk Kayu dan Abu Ampas Tebu pada Mortar terhadap Sifat Mekanik dan Sifat Fisisnya. Jurnal Ilmu Fisika. Vol (1) 32.

Prabowo, Aris. 2018. Pengaruh Stabilisasi Tanah Menggunakan Kapur dan Matos terhadap Kuat Geser dan Konsolidasi Tanah Gambut. Skripsi. Yogyakarta: Fakultas Teknik Sipil dan Perencanaan. Universitas Islam Indonesia.

Prasetyo, Yanwar E., Zaika, Yulvi., dan Rachmansyah, Arief. 2018. Pengaruh Penambahan Abu Ampas Tebu dan Kapur terhadap Karakteristik Tanah Lempung Ekspansif di Bojonegoro. Jurnal Mahasiswa Jurusan Teknik Sipil Universitas Brawijaya. Vol. 12 (2) 118-125. ISSN 1978 - 5658. 